\title{
FUENTES DE INFORMACIÓN Y PLURALISMO POLÍTICO EN LA COBERTURA DE ASUNTOS EUROPEOS EN TELEVISIÓN
}

\section{News Sources and Political Pluralism in the Coverage of European Issues on Spanish Television}

\author{
Dra. Samia BENAISSA PEDRIZA \\ Investigadora científica. Universidad Complutense de Madrid, España \\ E-mail: samia.benaissa@ucm.es \\ (10) http://orcid.org/0000-0002-1708-3338
}

Fecha de recepción del artículo: 17/02/2017

Fecha de aceptación definitiva: 16/03/2017

\begin{abstract}
RESUMEN
La investigación analiza el uso de las fuentes de información en noticias televisivas sobre asuntos europeos y su relación con el pluralismo informativo y político mediante la observación directa de una muestra de piezas seleccionadas. Los resultados revelan que los representantes de las élites políticas y gubernamentales siguen ocupando un lugar relevante en el espacio informativo. Además, su visibilidad se favorece mediante el empleo de formatos como el total o técnicas de coordinación entre las imágenes y la narración. Las fuentes cívicas, integradas por ciudadanos anónimos, alcanzan un grado de representación similar pero solo en piezas que incluyen citaciones directas. Por otra parte, un incremento del número y tipos de fuentes de información no genera necesariamente un mayor pluralismo político en las informaciones sobre asuntos europeos, ya que los medios españoles tienden a manifestar posiciones únicas y a menudo expresan una clara orientación europeísta.
\end{abstract}

Palabras clave: fuentes de información; asuntos europeos; pluralismo político; pluralismo informativo; noticias televisivas.

\begin{abstract}
The research analyses the use of information sources in television news on European issues and its relationship with political pluralism and pluralism of information through direct observation of a sample of selected stories. The results reveal that political and governmental representatives still occupy a relevant position in the informative space. In addition, the visibility of those sources is enhanced my means of individual appearances given on camera and through text-picture correspondence. Civic sources, consisting of anonymous citizens, reach a similar degree of representation but only in news including direct quotes. On the other hand, an increase of the number and types of news sources do not necessarily ensue a larger degree of political pluralism. To the contrary, it has been proved that Spanish television networks tend to express unique opinions in the news and often show a clear political orientation in favor of the European integration process.
\end{abstract}

Key words: news sources; European issues; political pluralism; pluralism of information; television news. 


\section{INTRODUCCIÓN Y SITUACIÓN ACTUAL}

La crisis de identidad que acusa la Unión Europea como organización internacional de cooperación en los últimos tiempos se ha convertido en uno de los principales objetivos informativos de los medios de comunicación del viejo continente. La información periodística sobre asuntos europeos está cobrando una mayor relevancia entre la opinión pública de la Unión Europea, que exige una cobertura objetiva y plural de los asuntos comunitarios en cada uno de los Estados miembros.

Como afirman los expertos (De Vreese, et al., 2001, pp. 107-122), ese interés manifiesto de la ciudadanía en la información generada por las instituciones europeas y los Estados miembros se ve correspondido por los medios de comunicación, quienes dedican cada vez más tiempo, espacio y atención a cubrir noticias sobre la Unión Europea (UE).

Por ello quizá sorprenda el reducido número de investigaciones científicas publicadas en el ámbito académico sobre el modo en que el proceso de integración europea es cubierto por los medios de comunicación nacionales de los Estados miembros.

Los escasos estudios existentes se han centrado fundamentalmente en describir la visión europeísta o anti europeísta que expresan los medios (Pradel, 2008, pp. 250-251) o en observar las diferencias en la cobertura mediática de los asuntos europeos (si esta es disonante, la opinión del espectador no se verá afectada; si el tratamiento mediático coincide o se replica, la audiencia se inclinará a favor de la orientación efectivamente transmitida) (Peter, 2004, p. 144). Existe, por tanto, un amplio campo de estudio por explorar en el ámbito del tratamiento informativo de los asuntos comunitarios, y en particular en lo que se refiere al medio televisivo.

En la presente investigación se decidió acotar la observación de un campo de estudio concreto de esa extensa realidad mediática y centrarlo en el análisis del pluralismo informativo y político de la información sobre asuntos europeos a través del uso de las fuentes de información periodística. Con ese fin la investigación toma como objeto de análisis las informaciones elaboradas y emitidas en España por los principales informativos de televisión generalista a lo largo de cuatro semanas consecutivas durante el primer trimestre del año 2016.

Si bien los estudios sobre el uso de las fuentes de información periodística en noticias de televisión son abundantes desde los años sesenta del pasado siglo, estos se centran en analizar un tipo de información concreta como las noticias de naturaleza política, medioambiental o las crónicas de sucesos, publicadas mayoritariamente en los medios de comunicación estadounidenses. En Europa se registra un número escaso de investigaciones sobre el tratamiento de la información europea en el medio televisivo y aun menor sobre el análisis de las fuentes de información periodística en este tipo de piezas informativas. Algunos trabajos en España (Humanes, et al., 2013, p. 572) han abordado el estudio del denominado «pluralismo interno» de los medios, entendido este como el grado de diversidad en los puntos de vista presentes en el discurso periodístico de naturaleza informativa, aunque no se aborda un estudio concreto de las distintas fuentes de información ni se discrimina en función del tipo de información especializada.

Por otra parte, el paralelismo entre el grado de pluralismo informativo y el político también es un clásico en los estudios sobre géneros periodísticos informativos (Hallin y Mancini, 2004). Sin embargo, la mayoría de los trabajos científicos llevados a cabo se centran en el análisis de noticias de tipo político en medios escritos de países ajenos al entorno europeo. Tampoco se han detectado estudios de este tipo desarrollados en España en relación con el medio televisivo.

Como marco teórico para el estudio de las fuentes de información se tomaron en consideración los trabajos publicados desde finales de la década de 1970 en el ámbito académico anglosajón relativos al vínculo entre las fuentes oficiales y las fuentes cívicas. La investigación analizó el papel que juegan 
las fuentes en los géneros informativos televisivos sobre la base de las investigaciones más relevantes sobre fuentes de información oficiales y de las élites (Tuchman, 1978; Fishman, 1980; Lawrence, 2000; Shehata, 2007; Watts y Maddison, 2014, p. 109) y cívicas (Papas, 1991; Lewis, et al., 2004, p. 160; Dimitrova y Strömback, 2009, pp. 149-166; Hopmann y Sherata, 2011, p. 662).

También se revisaron los distintos estándares comunicativos que ambas categorías de fuentes han terminado por configurar. Así, se tomaron en cuenta los principales modelos descritos por la doctrina sobre la preeminencia de los distintos tipos de fuentes empleadas en las informaciones periodísticas: el anglosajón, en el que abundan las fuentes políticas, gubernamentales u oficiales (Gans, 1979; Power y Self, 2003, p.101) y el que promueve una presencia proporcionada de fuentes oficiales y cívicas (Papas, 1991; Cross, 2010, p. 419).

\section{OBJETIVOS E HIPÓTESIS}

La investigación tiene como objetivo principal comprobar el grado de pluralismo informativo de las piezas emitidas sobre asuntos europeos en televisión, así como determinar las características de la relación existente entre las fuentes de información y el grado de pluralismo político presente en este tipo de información especializada.

Entre los objetivos de la investigación también figura comprobar en qué modelo informativo se incluye la cobertura actual de los asuntos comunitarios por los medios españoles: en el modelo anglosajón dominante, basado en una preeminencia de fuentes políticas, gubernamentales u oficiales (Tuchman, 1978; Gans, 1979; Fishman, 1980; Lawrence, 2000; Power y Self, 2003, p. 101; Shehata, 2007, p. 149; Watts y Maddison, 2014, p. 109) o bien dentro del modelo que defiende un equilibrio entre las fuentes cívicas y políticas (Schlesinger,1990 en Ferguson, 1990, pp. 61-83; Papas, 1991; Cross, 2010, p. 419).

Teniendo en cuenta lo anterior, se enuncian las dos hipótesis de la investigación:

- H1: Los medios televisivos españoles difunden piezas informativas sobre asuntos europeos con una pluralidad de fuentes de información relativa.

- H2: Los medios televisivos españoles elaboran piezas informativas que no reflejan un pluralismo político acorde con la actual realidad política europea.

\section{MetodologíA Y FUENTES}

El estudio empleó el método cuantitativo aplicado al análisis de las fuentes de información periodística en televisión. Se diseñó un modelo multifactorial del tipo 2x9x3 (fuentes directas/indirectas x tipología de fuentes ( 9 tipos) x 3 formatos -totales, VTR, conexión telefónica-) para llevar a cabo el análisis de los factores que indicasen la presencia de un pluralismo informativo en las piezas editadas por cada cadena de televisión analizada.

Para efectuar el análisis del pluralismo político en las piezas seleccionadas se diseñó un modelo $4 \times 9$ (4 tipos de noticias sobre asuntos europeos x tipología de fuentes -9 tipos-).

La técnica de investigación utilizada fue la observación directa de un conjunto de piezas informativas seleccionadas. Se decidió escoger una muestra de tamaño relativamente reducido que fuese representativa de la actualidad informativa europea. Por ello se verificó que en el período de tiempo acotado para seleccionar la muestra no se produjera una concentración de hechos informativos sobre asuntos europeos especialmente significativos que pudiese alterar los resultados de la investigación. 
La duración temporal de la muestra fue de 21 días repartidos a lo largo de cuatro semanas consecutivas de los meses de febrero y marzo de 2016. La fecha seleccionada para el inicio de las grabaciones se escogió al azar. Las piezas se grabaron de los informativos del mediodía y la noche de las cinco principales cadenas españolas de televisión generalista (Televisión Española, Antena 3, Telecinco, Cuatro y La Sexta) desde el 17 de febrero hasta el 08 de marzo de 2016. Se registró la totalidad de las piezas informativas sobre asuntos europeos emitidas de lunes a domingo.

La unidad de análisis fue la pieza informativa independiente, caracterizada por un formato, género y duración propios, con independencia de su inclusión o no en una serie de informaciones consecutivas agrupadas con el fin de construir un relato más completo sobre un determinado hecho informativo.

Se efectuó un análisis del contenido de las unidades de análisis centrado en las fuentes de información y por consiguiente no se realizó un análisis del discurso periodístico. Cada unidad fue posteriormente codificada en función de las categorías de análisis (fuentes directas e indirectas ${ }^{1}$, tipología de fuentes ${ }^{2}$, número de fuentes, formatos, tipos de informaciones sobre la Unión Europea).

Las fuentes de la investigación fueron primarias, entendidas como productos originales, elaborados a diario por los distintos medios de comunicación objeto de estudio. Estos incluyeron noticias, reportajes y otros géneros discursivos que se emitieron en los informativos de televisión durante el período de tiempo analizado.

Las piezas informativas fueron seleccionadas entre el total de piezas de los informativos en función de su temática (información especializada sobre la Unión Europea). Dentro de esta categoría se incluyeron, entre otras, noticias centradas exclusivamente en informaciones procedentes de los órganos e instituciones de la UE, otras que reflejasen posturas políticas alternativas a las posiciones oficiales comunitarias, hechos informativos que afectaran a España desde una perspectiva europea y finalmente, hechos noticiosos ocurridos en otros Estados miembros que revistieran un interés comunitario.

Esta concreta clasificación de las piezas sobre asuntos europeos se elaboró con la finalidad de recabar datos precisos sobre la variedad de fuentes de información periodística detectada en este tipo de información especializada y determinar su eventual vinculación con el grado de pluralismo político registrado en la Unión Europea en un momento actual mucho más complejo en relación con otras épocas históricas.

\section{RESUltados}

\subsection{Pluralismo informativo}

El análisis del pluralismo informativo se efectuó sobre una muestra de 78 piezas informativas con noticias, crónicas y reportajes sobre asuntos de temática europea y comunitaria. La muestra de piezas analizadas se caracterizó por incluir tanto fuentes directas (sujetos que emitieron declaraciones directamente a cámara) como fuentes indirectas (mencionadas en la narración). Para el estudio se seleccionaron tres categorías de informaciones: noticias que incluyeron como mínimo una fuente directa, noticias que citaron al menos una fuente indirecta y noticias que contuvieran fuentes de naturaleza directa e indirecta en la misma pieza. La categoría de noticias con fuentes directas fue la más numerosa, seguida por la categoría de noticias con fuentes indirectas y por último, la categoría de noticias con fuentes directas e indirectas.

\footnotetext{
${ }^{1}$ Se analizaron las fuentes directas (sujetos que aparecieron en las piezas informativas efectuando declaraciones, estuviesen o no identificados mediante un rótulo identificativo) y fuentes indirectas, entendiendo por tales las que se mencionan en el relato periodístico por el narrador (locutor, voz en off o periodista), estuvieran o no apoyadas por imágenes en la pieza informativa.

${ }^{2} \mathrm{La}$ investigación analizó los nueve tipos de fuentes que surgieron en las piezas seleccionadas: políticas, gubernamentales, institucionales, cívicas (ciudadanos anónimos), sociedad civil (asociaciones y ONG), agentes sociales (asociaciones de empresarios), expertos, mediáticas y estadísticas/documentales.
}

(C) Ediciones Universidad de Salamanca / CC BY - NC ND $\quad$ Fonseca, Journal of Communication, n. 14, 2017, pp. 181-201 


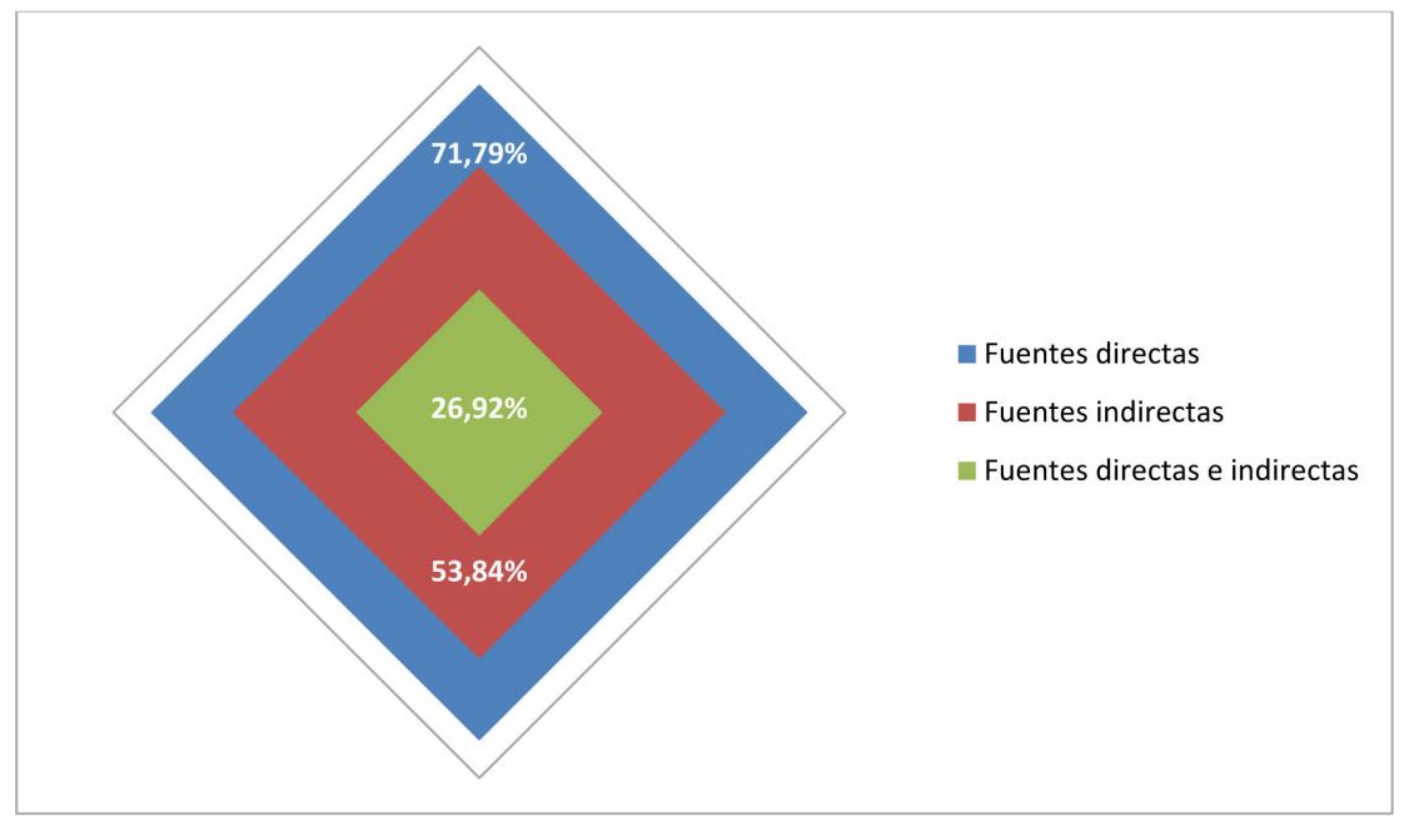

Gráfico n. ${ }^{\circ}$ 1. Categoría de noticias según el tipo de fuente

Fuente: elaboración propia.

\subsubsection{NOTICIAS CON FUENTES DIRECTAS}

De la muestra de 78 informaciones grabadas, 56 incluyeron fuentes directas, lo que representa el $71,79 \%$ de los casos. La media de fuentes directas citadas por pieza fue de 2,14.

Obviamente se advierte una predominancia de fuentes que realizan declaraciones directamente a cámara por la influencia informativa que ejercen los actores que aparecen en los medios, ya que como afirman Fico y Soffin (1994, pp. 64-76) estos contribuyen a centrar la atención del público en determinados puntos de vista y a enfatizar otros.

El papel que juegan las fuentes en los géneros informativos en televisión ha sido debatido por un buen número de expertos, que se dividen entre aquellos que afirman que no todas las fuentes obtienen la misma atención por parte de los medios (Hall, et al., 1978; Gans, 1979; Hackett, 1985) y que en el discurso periodístico abundan las fuentes oficiales y de las élites (Lawrence, 2000; Shehata, 2007), y aquellos que opinan que también se recurre con asiduidad a otras fuentes formadas por expertos o ciudadanos interrogados en espacios públicos (Schlesinger, 1990 en Ferguson, 1990, pp. 61-83).

En la observación de las fuentes directas en la investigación se identificaron ocho tipos de fuentes, lo que a priori contrasta con la opinión de cierto sector doctrinal que advierte que en el medio radiofónico y en el televisivo se tiende a reducir la diversidad de fuentes de información y centrar la atención en las fuentes de tipo gubernamental (Watts y Maddison, 2014, p. 109). 
Gráfico n. ${ }^{\circ}$ 2. Tipología de fuentes directas

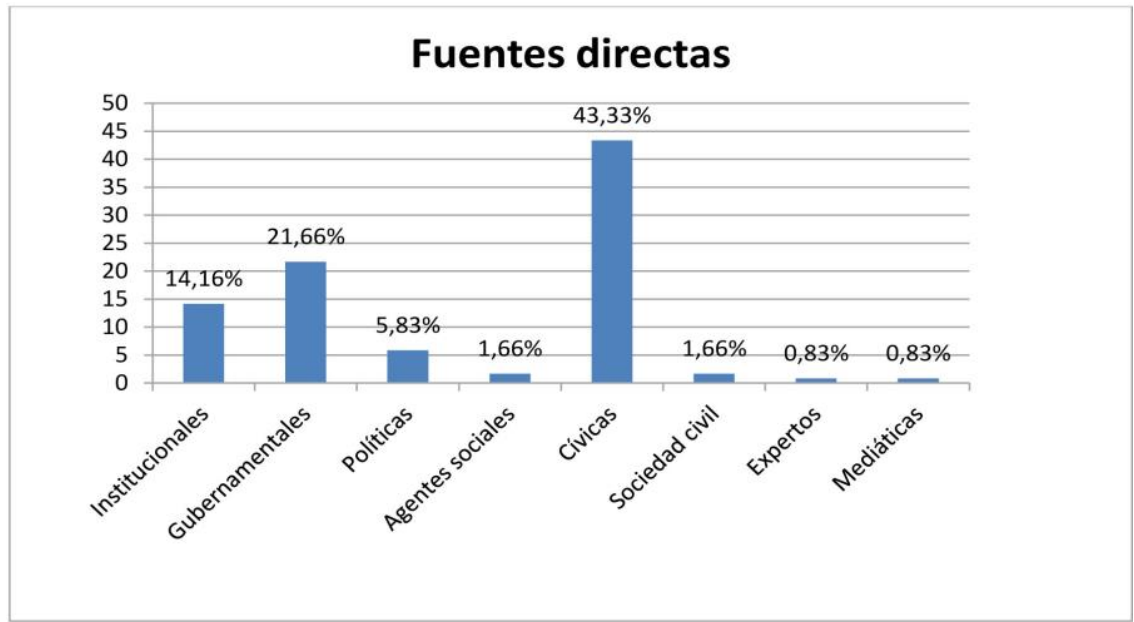

Fuente: elaboración propia.

Tabla n. ${ }^{\circ}$ 1. Tipología de fuentes directas (desglose)

\begin{tabular}{|c|c|c|c|}
\hline $\begin{array}{l}\text { Fuentes } \\
\text { institucionales: }\end{array}$ & $\begin{array}{c}\text { Fuentes } \\
\text { comunitarias (UE) } \\
52,94 \%\end{array}$ & $\begin{array}{c}\text { Fuentes } \\
\text { internacionales } \\
\text { (otras OI) } \\
47,05 \%\end{array}$ & \\
\hline $\begin{array}{l}\text { Fuentes } \\
\text { gubernamentales: }\end{array}$ & $\begin{array}{c}\text { Gobiernos } \\
\text { internacionales } \\
7,69 \%\end{array}$ & $\begin{array}{l}\text { Gobierno nacional, } \\
\text { regional o local } \\
\text { (España) } \\
30,76 \%\end{array}$ & $\begin{array}{c}\text { Gobiernos de otros } \\
\text { Estados miembros } \\
\text { UE } \\
61,53 \%\end{array}$ \\
\hline Fuentes políticas: & $\begin{array}{l}\text { Partidos políticos } \\
\text { internacionales } \\
\text { Sin presencia }\end{array}$ & $\begin{array}{c}\text { Partidos políticos } \\
\text { nacionales (España) } \\
57,14 \%\end{array}$ & $\begin{array}{c}\text { Partidos políticos } \\
\text { de otros Estados } \\
\text { miembros UE } \\
42,85 \%\end{array}$ \\
\hline Fuentes civicas: & $\begin{array}{c}\text { Ciudadanía europea } \\
17,30 \%\end{array}$ & $\begin{array}{c}\text { Nacionales de Oriente } \\
\text { medio (refugiados) } \\
75 \%\end{array}$ & $\begin{array}{c}\text { Otros nacionales } \\
7,69 \%\end{array}$ \\
\hline Sociedad civil: & $\begin{array}{l}\text { ONGs } \\
92,85 \%\end{array}$ & $\begin{array}{c}\text { Otras asociaciones } \\
\text { civiles (vecinales) } \\
7,14 \%\end{array}$ & \\
\hline
\end{tabular}

Fuente: elaboración propia.

El total de fuentes formadas por representantes oficiales o élites político-económicas (conjunto de las fuentes gubernamentales, institucionales, políticas y agentes sociales) alcanzó el 43,31\%. Las fuentes cívicas, por su parte, representaron el 43,33\% de las fuentes directas. En principio no puede hablarse, por tanto, de una hegemonía de las fuentes oficiales o de las élites en el contenido informativo de los medios españoles sino más bien de una situación de relativo equilibrio, al menos en términos 
numéricos. En ese sentido, los resultados concuerdan con las últimas investigaciones llevadas a cabo en relación con la frecuencia de aparición de las fuentes cívicas y políticas en informativos de televisiones internacionales en abierto (Cross, 2010, p. 419).

El análisis de las fuentes directas en relación con los formatos se centró en la observación de totales, VTR y una conexión telefónica. No hubo directos que recogiesen este tipo de fuentes. El análisis conjunto de estas variables pretendía detectar la existencia de un eventual interés de los medios por visibilizar en mayor o menor medida un tipo determinado de fuente.

Gráfico n. ${ }^{\circ}$ 3. Fuentes directas y formatos televisivos

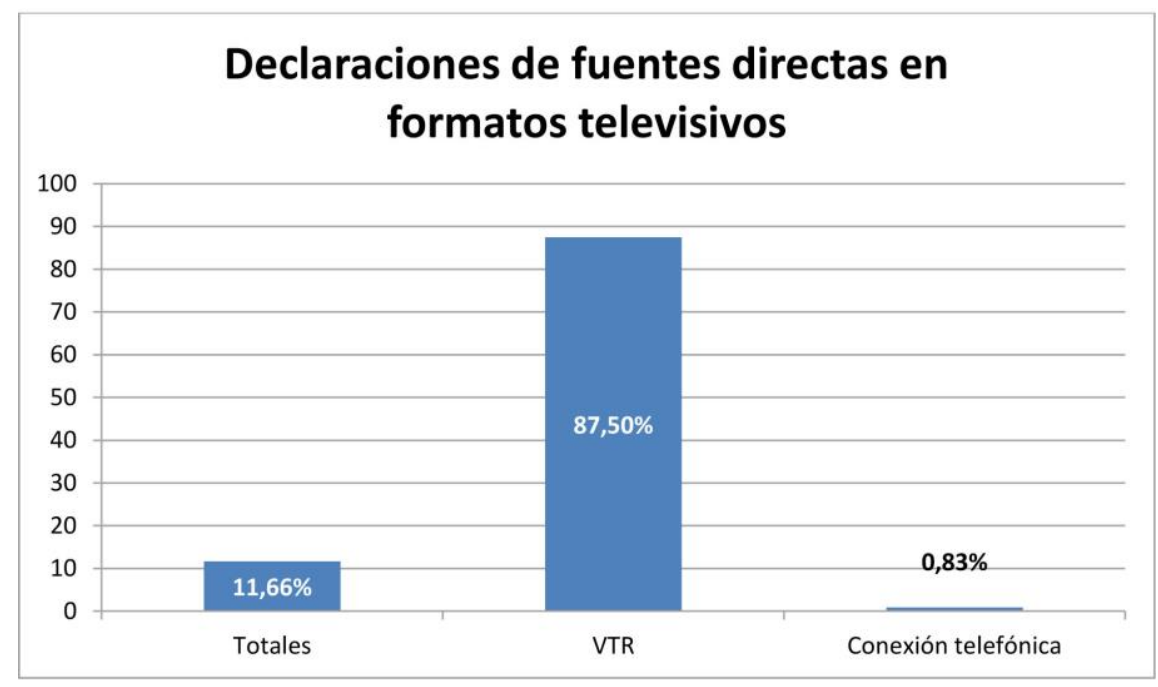

Fuente: elaboración propia.

Gráfico n. ${ }^{\circ}$ 4. Tipos de fuentes en el formato «Total»

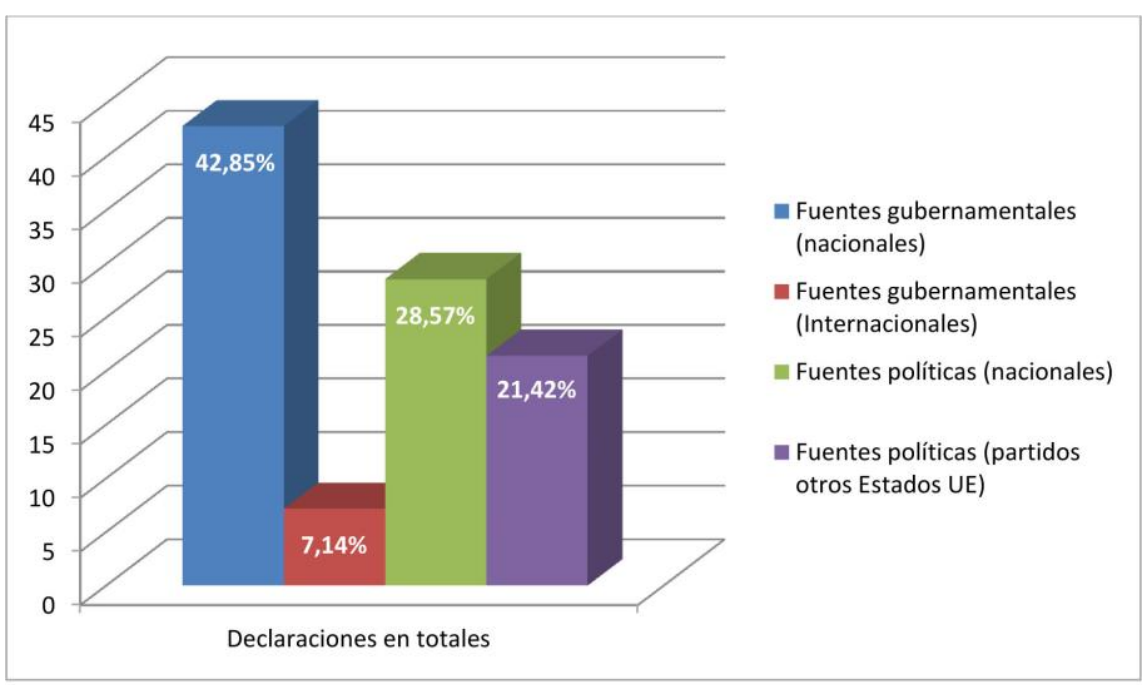


Fuente: elaboración propia.

Gráfico n. ${ }^{\circ}$. Tipos de fuentes en el formato «VTR»

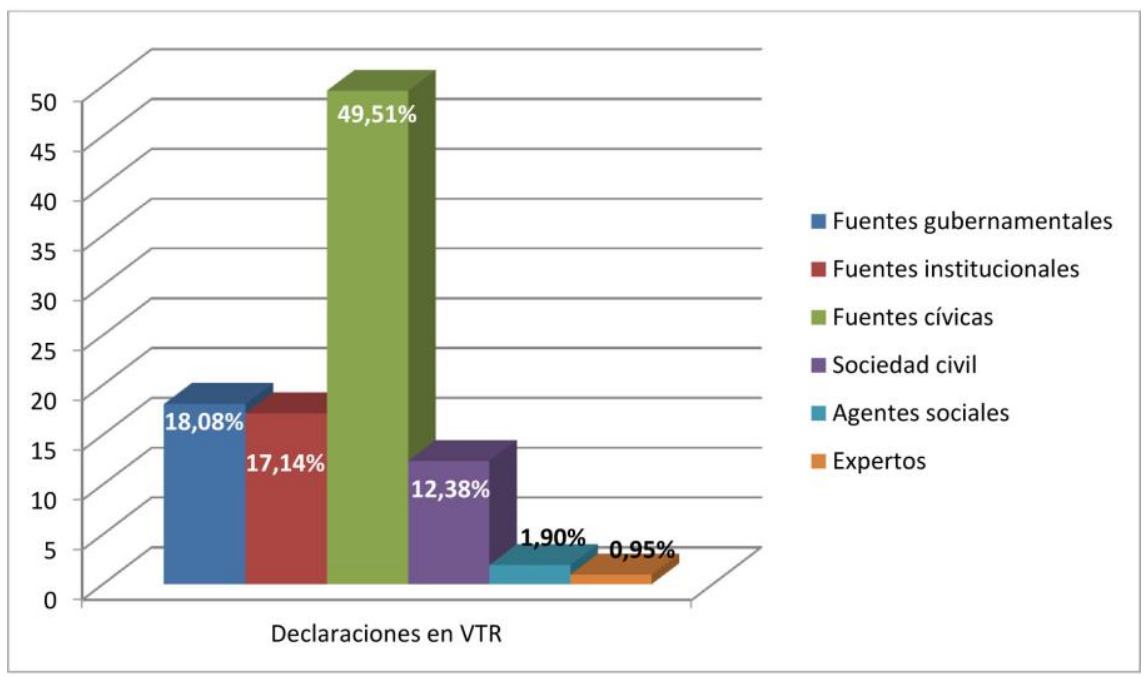

Fuente: elaboración propia.

Los totales se emplearon como un formato minoritario para transmitir declaraciones de fuentes directas. Las fuentes que aparecieron con mayor frecuencia en este formato fueron las gubernamentales nacionales (42,85\%). Le siguieron los políticos nacionales, los representantes de partidos políticos de otros Estados miembros de la UE y las fuentes gubernamentales internacionales.

Las declaraciones a cámara editadas dentro de un VTR fueron el formato más empleado en relación con las fuentes directas. Los tipos de fuentes más comunes que se difundieron mediante este formato fueron las fuentes cívicas (49,51\%). A gran distancia figuraron las fuentes gubernamentales, las institucionales, la sociedad civil, los agentes sociales y los expertos.

La única fuente mediática citada fue la de un periodista, emitida mediante otro tipo de formato -una conexión telefónica-.

Los resultados indican una cierta prevalencia en el uso del total para destacar las declaraciones de las fuentes oficiales (gubernamentales y políticas), especialmente las nacionales. El total sigue siendo un formato privilegiado para centrar la atención de la audiencia en determinados sujetos de la información en relación con otros formatos como el VTR, que fue empleado prioritariamente para introducir fragmentos de declaraciones de fuentes cívicas por las cadenas de televisión generalista españolas.

En definitiva, no se aprecia un uso diferenciado de las fuentes oficiales o de las élites en relación con las fuentes cívicas, aunque sí existe una tendencia a favorecer la visibilidad de las fuentes oficiales mediante el uso de determinados formatos como el total. Aunque en la muestra de piezas seleccionadas surgieron hasta ocho tipos de fuentes directas, su representación fue variable. Las fuentes cívicas, institucionales, gubernamentales y políticas resultaron ser muy numerosas. Sin embargo, otros tipos de fuentes de información como los expertos, los agentes sociales o los propios medios de comunicación resultaron ser prácticamente testimoniales. 


\subsubsection{NOTICIAS CON FUENTES INDIRECTAS}

El recurso a la citación indirecta de fuentes en la muestra analizada se detectó en una proporción menor, en concreto en el 53,84\% de los casos. La media de fuentes indirectas citadas por pieza fue de 1,80 .

Los tipos de fuentes indirectas que surgieron en la muestra seleccionada fueron ocho (los expertos no resultaron citados en ningún caso). Al contrario que las piezas editadas con fuentes directas, las más numerosas fueron las fuentes de tipo oficial o de las élites político-económicas (73,66\%). Las fuentes cívicas citadas de forma indirecta representaron sólo el 3,94\% de este tipo de fuente. La sociedad civil (ONG) fue citada escasamente. Las fuentes mediáticas solo se utilizaron para identificar la procedencia de las informaciones (agencias de noticias) y la propiedad de las imágenes emitidas en las piezas. Sin embargo, las fuentes estadísticas y documentales fueron citadas en un estimable porcentaje de casos.

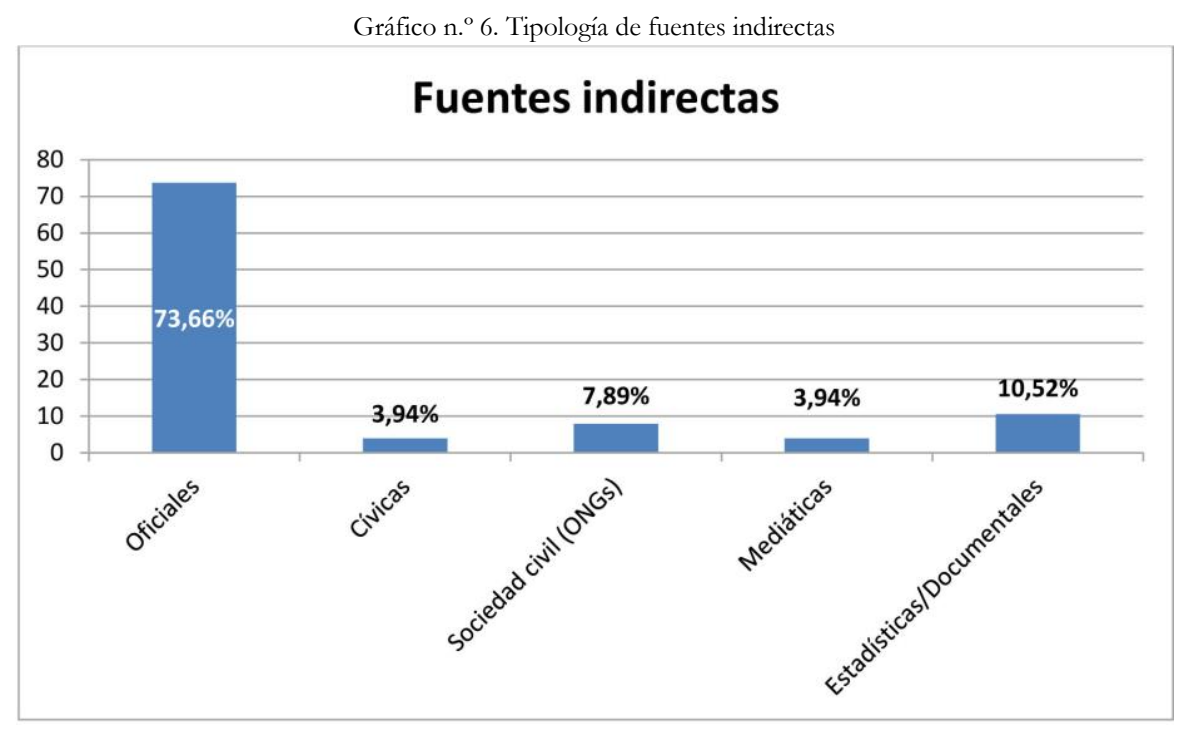

Fuente: elaboración propia.

Los resultados obtenidos en relación con las fuentes oficiales y de las élites en esta particular categoría de piezas informativas estarían en consonancia con las teorías formuladas por un sector doctrinal que a lo largo de las décadas ha venido sosteniendo que este tipo de fuentes son las que dominan el discurso informativo en perjuicio de las fuentes cívicas (consumidores, ciudadanos), tanto en los medios de comunicación tradicionales -medios escritos- (Power y Self, 2003, p. 101; Watts y Madison, 2014, p. 116) como en los audiovisuales (Tuchman, 1978; Fishman, 1980).

En relación con las fuentes documentales/estadísticas, la doctrina opina que la inclusión de este tipo de fuentes es positiva porque permite a los ciudadanos expresar su opinión ante los medios de comunicación (Deuze, 2002, p. 141). En la investigación se apreció un porcentaje significativo de representación de datos estadísticos y documentales provenientes tanto de consultoras privadas independientes como de informes de instituciones no gubernamentales de países terceros (Observatorio sirio de Derechos Humanos) así como de encuestas de opinión elaboradas por institutos esta- 
dísticos en los Estados miembros (encuestas sobre el «Brexit»). La práctica revela, por consiguiente, un uso de las fuentes documentales por los medios españoles no excesivamente centrado en las instancias oficiales.

La variable «formato» se analizó mediante la observación de los tipos de fuentes que fueron apoyadas por imágenes en los VTR de las piezas seleccionadas. Se pretendía conocer así el grado de relevancia que los medios conceden a cada tipo de fuente citada de forma indirecta. Solo resultaron apoyadas con imágenes las fuentes gubernamentales (nacionales, de los Estados miembros e internacionales), las institucionales (representantes de organizaciones internacionales y de la Unión Europea) y las políticas (políticos nacionales y de los Estados miembros de la UE). Las fuentes indirectas que estuvieron más apoyadas por imágenes emitidas durante el VTR fueron las de miembros de los gobiernos de los Estados miembros (53,33\%) seguidas por los representantes de otros gobiernos internacionales $(13,33 \%)$. El resto de fuentes indirectas oficiales solo fueron apoyadas por imágenes en un porcentaje inferior al $7 \%$.

En términos cuantitativos, los resultados revelan que existe una pluralidad de fuentes idéntica a la que se da en el ámbito de las fuentes directas, si bien la representación de cada tipo de fuente varía considerablemente. Las fuentes oficiales indirectas ocuparon una presencia informativa de casi dos tercios en relación con las demás fuentes, y en particular con las fuentes cívicas, cuyo punto de vista apenas fue incluido en el discurso. En ese sentido, los resultados podrían relacionarse con la proporción anunciada por Gans (1979), según la cual las fuentes de las élites ocupan 4/5 del tiempo de un informativo de televisión, mientras que las fuentes de origen desconocido (ciudadanos, individuos que protestan, víctimas, votantes, etc.) solo ocupan el $1 / 5$ restante.

En el análisis de las fuentes indirectas, los resultados de la investigación indican que las fuentes gubernamentales siguen ocupando una posición de particular relevancia para los medios televisivos españoles. Estos además emplean técnicas de refuerzo como la coordinación entre la narración y las imágenes de las fuentes oficiales en los VTR. Sin embargo, ciertos hallazgos también sugieren la existencia de un pluralismo informativo algo más significativo logrado mediante la inserción en las piezas de referencias documentales más numerosas, variadas y menos próximas a las instancias oficiales.

\subsubsection{INTERACCIÓN ENTRE FUENTES DIRECTAS E INDIRECTAS}

En la investigación se quiso analizar la relación entre las fuentes directas y las indirectas en el escaso $26,92 \%$ de piezas que contuvieron ambos tipos de fuentes. La proporción de fuentes directas citadas fue mayor $(61,22 \%)$ que las indirectas. La media de fuentes citadas por pieza fue de 3,85. 


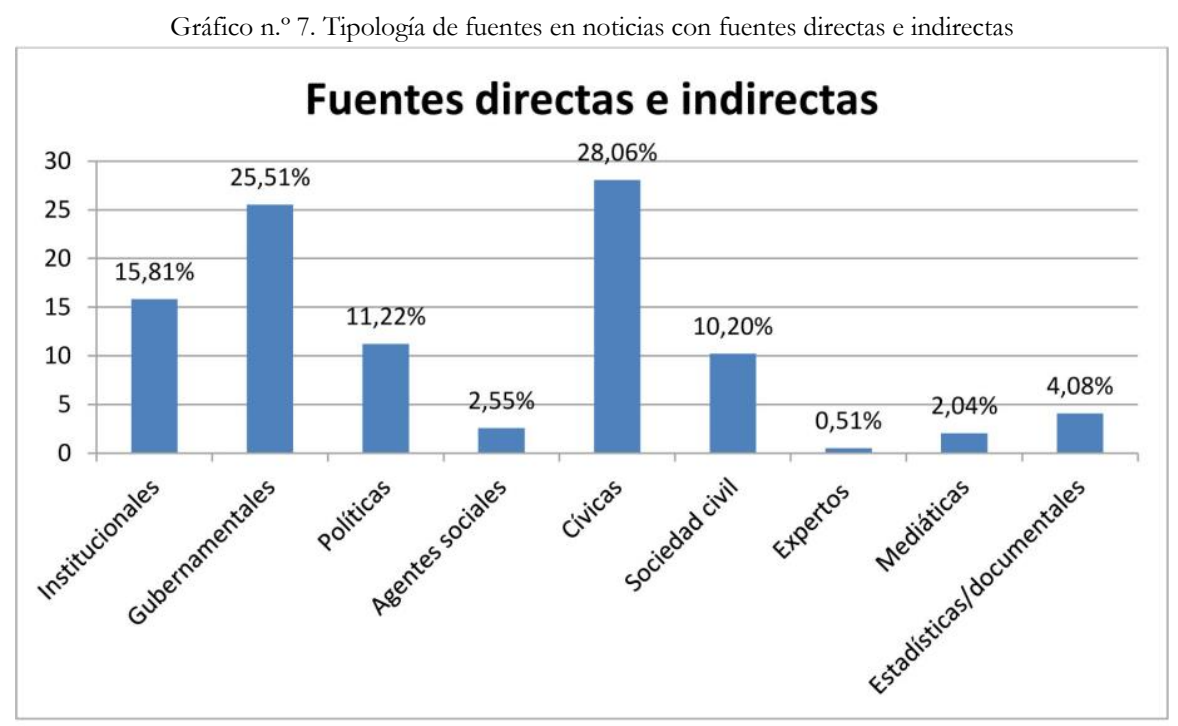

Fuente: elaboración propia.

Tabla n. ${ }^{\circ}$ 2. Tipología de fuentes en noticias con fuentes directas e indirectas (desglose)

\begin{tabular}{|c|c|c|c|}
\hline $\begin{array}{l}\text { Fuentes } \\
\text { institucionales: }\end{array}$ & $\begin{array}{c}\text { Fuentes } \\
\text { comunitarias (UE) } \\
48,38 \%\end{array}$ & $\begin{array}{c}\text { Fuentes } \\
\text { internacionales } \\
\text { (otras OI) } \\
51,61 \%\end{array}$ & \\
\hline $\begin{array}{l}\text { Fuentes } \\
\text { gubernamentales: }\end{array}$ & $\begin{array}{c}\text { Gobiernos } \\
\text { internacionales } \\
10 \%\end{array}$ & $\begin{array}{l}\text { Gobierno nacional, } \\
\text { regional o local } \\
\text { (España) } \\
18 \%\end{array}$ & $\begin{array}{c}\text { Gobiernos de otros } \\
\text { Estados miembros } \\
\text { UE } \\
72 \%\end{array}$ \\
\hline Fuentes políticas: & $\begin{array}{l}\text { Partidos políticos } \\
\text { internacionales } \\
\text { Sin presencia }\end{array}$ & $\begin{array}{c}\text { Partidos políticos } \\
\text { nacionales (España) } \\
59 \%\end{array}$ & $\begin{array}{l}\text { Partidos políticos } \\
\text { de otros Estados } \\
\text { miembros UE } \\
40,90 \%\end{array}$ \\
\hline Agentes sociales: & $\begin{array}{c}\text { Asociaciones de } \\
\text { empresarios } \\
\text { nacionales (España) } \\
100 \%\end{array}$ & & \\
\hline
\end{tabular}

Fuente: elaboración propia.

El conjunto de fuentes oficiales y de las élites político-económicas alcanzó el 55,09\% del total. Entre estas figuran las institucionales de naturaleza comunitaria que representaron el 13,88\% de la suma de fuentes oficiales, lo que no parece indicar una preferencia actual de los medios televisivos 
españoles por emplear fuentes comunitarias, incluso en informaciones sobre asuntos estrictamente europeos.

Sin embargo, las fuentes gubernamentales representaron el 46,29\% del total de fuentes oficiales. En este tipo de fuentes, los medios favorecieron por encima de toda la presencia de los representantes de los gobiernos de los Estados miembros. Se detectó la misma conducta respecto a las fuentes políticas integradas por representantes de los partidos políticos de los distintos Estados miembros, netamente superiores en número a los políticos nacionales. Los resultados se interpretan en el sentido de que los medios españoles expresan una orientación europeísta en el uso de las fuentes de información de carácter oficial pero cuando las televisiones españolas informan sobre la UE evitan centrarse excesivamente en posturas institucionales.

Las fuentes cívicas se pusieron en relación con el resto de fuentes y en particular con las fuentes oficiales y de las élites político-económicas. Como afirman Hopmann y Shehata (2011, pp. 657-658) el estudio de las fuentes cívicas no ha sido objeto de una especial atención por parte de los expertos y prácticamente solo se han abordado investigaciones en las que este tipo de fuente era observada en solitario en informativos de televisión, pero sin ser relacionadas en informaciones junto a otro tipo de fuentes (Lewis y Wahl-Jorgensen, 2005, pp. 98-108; Lewis, et al., 2004, pp. 153-164).

Tras practicar el análisis se observó que los resultados mantienen un paralelismo con los registrados en los escasos trabajos llevados a cabo sobre informativos de televisión generalista en el continente europeo. El porcentaje de fuentes cívicas fue similar al contabilizado por Papas (1991) en un estudio que reveló que los ciudadanos comunes ocupaban el 25\% del espacio-tiempo televisivo. Los hallazgos también se acercan a lo que Hopmann y Shehata (2011, p. 662) comprobaron entre 1994 y 2007 en relación con las fuentes cívicas que aparecieron en los informativos daneses de televisión. Estas representaron $1 / 5$ parte de las fuentes de información periodística, siendo además el segundo tipo de fuente más citado tras las fuentes de naturaleza política. Igualmente, los resultados coinciden con la investigación llevada a cabo por Dimitrova y Strömback (2009, pp. 149-166) quienes descubrieron que el porcentaje de fuentes cívicas en las noticias de los informativos suecos era del $25 \%$ (frente al 57\% de fuentes oficiales en noticias políticas nacionales).

El comportamiento de las fuentes cívicas en la presente investigación podría entenderse que ha sido replicado en parte, si bien existen diferencias notables que deberían tenerse en cuenta, principalmente el hecho de que los estudios anteriores se hayan centrado en analizar noticias políticas o generales dentro de un informativo de televisión y no un tipo particular de información como es la que versa exclusivamente sobre asuntos europeos.

Las fuentes representativas de la sociedad civil (varias ONG y una asociación de vecinos) alcanzaron un $10,20 \%$ del total de fuentes de información. Esta cifra solo es comparable con un estudio aislado llevado a cabo por Owens (2008, p. 365) en relación con la presencia de activistas en las informaciones de la televisión norteamericana y que reveló que estos solo representan un $6 \%$ del total de las fuentes televisivas.

Los expertos no alcanzaron ni $1 \%$ de la representación total de fuentes, a pesar de que según la doctrina constituyen el grueso de la confianza que los espectadores depositan en una fuente de información, además de resultar de fácil acceso para los medios (Miller y Kurpius, 2010, pp. 138-139; 149). Los resultados registrados en España no coinciden con lo afirmado por estos autores respecto a su frecuencia mediática de uso, ni tampoco con lo que descubrieron Dimitrova y Strömback (2009, pp. 149-166) en Suecia respecto a que los expertos aportados por las televisiones aparecen como fuente autorizada en el $10 \%$ de las noticias. 


\subsection{Pluralismo político}

El análisis de la relación entre las fuentes periodísticas y el grado de pluralismo político en la información televisiva sobre asuntos europeos se llevó a cabo mediante el análisis de cuatro tipos de noticias que por sus características permitirían detectar con mayor fiabilidad la existencia de distintas posturas sobre el proceso de integración europeo. Del conjunto de la muestra de la investigación se analizaron noticias que versasen estrictamente sobre asuntos institucionales y políticas comunitarias, informaciones que expresasen puntos de vista alternativos al proceso de integración europeo, noticias nacionales narradas en clave europea y posturas de otros Estados miembros frente a problemas de interés común.

Gráfico n. ${ }^{\circ}$. Clasificación de noticias sobre asuntos comunitarios

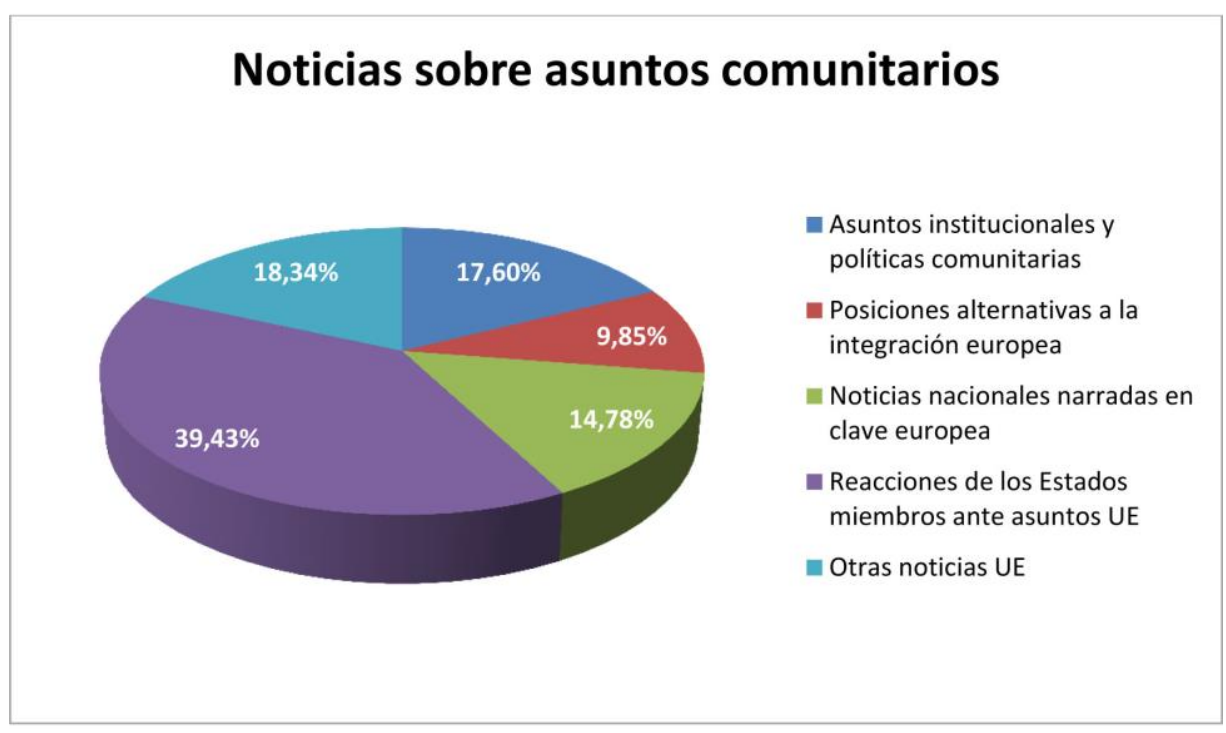

Fuente: elaboración propia.

\subsubsection{EUROCENTRISMO INSTITUCIONAL}

La primera clase de hechos informativos analizados fueron los generados por los propios órganos e instituciones comunitarias. El porcentaje de noticias de esta categoría en relación con el total de noticias fue de $17,60 \%$. La tipología de fuentes en este tipo de informaciones se redujo a seis categorías y la media de fuentes citadas por pieza fue de 1,44. Las fuentes más citadas fueron las de carácter institucional comunitario $(27,77 \%)$, seguidas de las fuentes institucionales internacionales $(22,22 \%)$, y en mucha menor medida por la sociedad civil, las fuentes cívicas, gubernamentales nacionales e internacionales, agentes sociales y mediáticas (por ese orden).

La figura de los representantes de las instituciones y órganos comunitarios europeos es una fuente informativa escasamente tratada por los expertos y cuya observación se ha reducido al análisis de acontecimientos de gran impacto político en el devenir del proceso de integración europeo. Peter, Laud y Semetko (2004, p. 416) fueron los primeros en estudiar la presencia televisiva de los represen- 
tantes institucionales de la UE en la cobertura informativa de las elecciones al Parlamento Europeo de 1999 en catorce Estados miembros. Sin embargo, sus resultados arrojaron grandes diferencias entre países, ya que mientras en España la presencia de este tipo de fuente informativa dominó la escena mediática, en el resto de Estados miembros fueron prácticamente invisibles, a excepción de Austria.

Los resultados de la presente investigación parecen confirmar las conclusiones formuladas por Peter, Laud y Semetko (2004, p. 416) para el caso español, si bien es preciso tener en cuenta que su estudio se desarrolló en un contexto informativo marcado por acontecimientos europeos de carácter extraordinario, que sin duda pueden llegar a influir en las rutinas productivas de los medios de comunicación de los Estados miembros. En el período temporal de la investigación, mucho más neutro desde un punto de vista informativo, los principales hechos noticiosos sobre actos de las instituciones europeas que ocurrieron fueron decisiones de tipo económico, de política comercial respecto a terceros estados, sobre cuestiones migratorias y libertad de circulación dentro del espacio Schengen.

De cualquier modo, los resultados indican que en este tipo de noticias los medios televisivos españoles siguen privilegiando a las fuentes oficiales y de las élites que representaron el 61,08\% del total de fuentes citadas. No obstante, lo anterior, y a pesar de la presencia mayoritaria de las fuentes institucionales, se aprecia una intencionalidad por parte de las distintas cadenas de televisión analizadas en ofrecer puntos de vista externos y situar en un nivel cercano a los representantes de los órganos e instituciones comunitarias y a los representantes de otras organizaciones internacionales en informaciones sobre asuntos puramente comunitarios.

\subsubsection{POSICIONES ALTERNATIVAS AL PROCESO DE INTEGRACIÓN EUROPEO}

Las noticias que reflejaron posiciones políticas, económicas o sociales alternativas al proceso de integración europeo representaron un escaso $9,85 \%$ del total de piezas informativas analizadas. Se pretendía detectar la presencia de movimientos político-sociales de nueva creación, propuestas socioeconómicas alternativas y, en general, cualquier postura distinta a la oficial defendida por los distintos actores políticos europeos (euroescepticismo, eurofobia, independentismos, populismos, políticas antiausteridad, etc.). Pero en la práctica solo surgió un tema único de discusión tratado por el conjunto de cadenas: la propuesta de un «Plan B para Europa», presentada en Madrid por el exministro de finanzas griego Yannis Varoufakis.

La media de fuentes de información citadas por pieza fue de 2,35 y las categorías de fuentes que se incluyeron en ellas fueron solo cinco (gubernamentales, políticas, cívicas, mediáticas y estadísticas/documentales). Las fuentes más citadas fueron los representantes de partidos políticos nacionales y de los Estados miembros en pie de igualdad (27,27\% en ambos casos), seguidas por los representantes de los gobiernos de los Estados miembros (24,24\%), y en porcentajes inferiores al $10 \%$ el resto de fuentes.

En las noticias sobre la propuesta de un «Plan B para Europa» se comprobó la ausencia de posiciones contrarias o plurales sobre el plan económico alternativo propuesto por el ideólogo griego, ya que todas las informaciones de las cadenas confluyeron en una posición única. Además, el 50\% de las noticias incluyeron una única fuente para informar acerca de la propuesta de Yannis Varoufakis. El $33,33 \%$ de las noticias introdujeron dos fuentes y solo un 16,66\% incluyeron cuatro fuentes. 


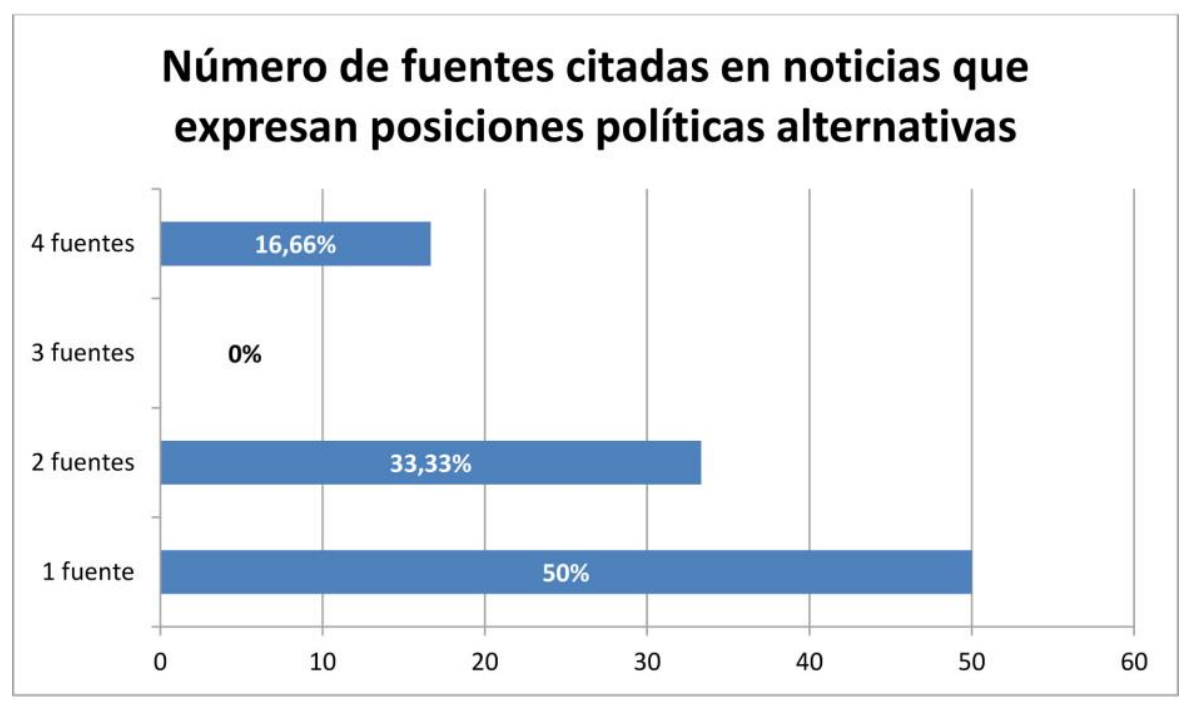

Fuente: elaboración propia.

Los resultados reflejan un escaso pluralismo informativo además de político en este tipo de noticias. A pesar de incluir un número mayor de fuentes en las piezas, los medios confluyeron en posiciones políticas únicas expresadas mayoritariamente por fuentes de las élites político-económicas. Por otra parte, la presencia marginal de fuentes cívicas indica una ausencia de interés de los medios por incluir en las piezas opiniones alternativas de la ciudadanía sobre la evolución del proceso de integración europeo.

\subsubsection{NACIONALIZACIÓN DE ASUNTOS EUROPEOS}

Es un hecho contrastado que las noticias internacionales se tienden a ver por los medios a través de perspectivas nacionales (Riegert, 2011, p. 1567; De Vreese, et al., 2001, pp. 107-122; Rössler, 2004, p. 289). Por ello en la investigación se analizaron informaciones que abordaron posiciones nacionales ante cuestiones europeas. Estas constituyeron el 14,78\% del total de noticias analizadas durante la investigación. Mediante el examen de este tipo de piezas se pretendía confirmar la existencia de la tradicional tendencia a la «nacionalización» de los asuntos europeos, una práctica informativa habitual en los medios de comunicación de los Estados miembros y que es también indicativa de una determinada orientación política.

La media de fuentes citadas por pieza en las noticias nacionales narradas en clave europea fue de 1,71 y las categorías de fuentes citadas fueron siete: representantes de las instituciones comunitarias y de otras organizaciones internacionales, miembros del gobierno español y de los Estados miembros, políticos españoles y de otros partidos de los Estados miembros, agentes sociales, ciudadanos de la UE, sociedad civil y fuentes estadísticas/documentales.

Las fuentes más citadas fueron los ciudadanos europeos $(27,77 \%)$ seguidos por los políticos españoles $(19,44 \%)$ y la sociedad civil -ONG- (13,88\%). En ese sentido, los resultados estarían en la línea abierta por las investigaciones practicadas en los medios televisivos anglosajones y que apuntan a que en las noticias de tipo político los ciudadanos aparecen con mayor frecuencia (Lewis, et al., 2004, 
p. 160) porque los hechos noticiosos afectan cada vez de forma más directa a la ciudadanía (Hjarvard, 2006 en Hopmann y Shehata, 2011, p. 660). Entre las noticias pertenecientes a esta categoría figuraron, entre otras, la posición del gobierno español en el Consejo Europeo sobre el «Brexit», las manifestaciones ciudadanas en España ante la crisis migratoria de los refugiados y las opiniones de empresarios españoles sobre la suspensión temporal del acuerdo Schengen. Muchas de ellas noticias nacionales con perspectiva europea que implicaban consecuencias directas para la vida cotidiana de los ciudadanos españoles.

En todo caso, la existencia de un porcentaje cercano al 15\% de informaciones centradas en difundir reacciones nacionales frente a políticas y decisiones comunitarias confirma una tendencia no demasiado acusada a la «nacionalización» de los asuntos europeos por parte de los medios televisivos españoles. El uso de las fuentes de información refleja un pluralismo informativo relativo y un pluralismo político caracterizado en este caso por una mayor presencia de las opiniones de los ciudadanos y de la sociedad civil en detrimento de las fuentes oficiales.

\subsubsection{LA PERSPECTIVA INFORMATIVA DE LOS ESTADOS MIEMBROS}

La mayor presencia en los informativos de televisión de hechos noticiosos ocurridos en los Estados miembros que reflejaran una reacción ante un acto o decisión comunitaria indicaría el interés de los medios por informar sobre aspectos de la realidad europea desde otras perspectivas distintas a la nacional. En ese sentido la investigación perseguía detectar la existencia de conductas opuestas a la llamada «nacionalización» de los asuntos europeos, analizada previamente.

El porcentaje de noticias de este tipo registradas en el total de piezas analizadas en la investigación fue considerable (39,43\%). La media de fuentes citadas por pieza fue de 1,62 y las categorías de fuentes citadas fueron ocho: institucionales comunitarias y de organizaciones internacionales, miembros del gobierno español, de los Estados miembros y de terceros estados, políticos nacionales y de los Estados miembros, agentes sociales, sociedad civil, fuentes cívicas, mediáticas y estadísticas/documentales.

Las fuentes de los gobiernos de los Estados miembros fueron las más numerosas (32,96\%) seguidas por las cívicas $(25,26 \%)$. El resto de fuentes citadas lo fueron en porcentajes poco significativos entre el $1 \%$ y el $7 \%$. Los resultados muestran una tendencia persistente a favorecer la presencia de fuentes oficiales en perjuicio de la ciudadanía europea (que solo apareció citada en el 3,29\% de las ocasiones) y en menor medida de otros nacionales de terceros estados $(21,97 \%)$, a pesar de que resultaron ser protagonistas directos de muchas noticias de esta categoría, centradas en el desarrollo de la crisis de los refugiados en Europa y el «Brexit». La menor participación de las fuentes de origen ciudadano en este tipo de piezas informativas confirmaría las teorías de Tuchman (1978) y Gans (1979) formuladas hace ya más de tres décadas sobre el limitado acceso real de la gente común a los medios en calidad de fuentes de información reconocida.

En las piezas sobre el «Brexit» se pudieron identificar claramente distintas posiciones políticas reflejadas a través de distintas fuentes de información. El 78,57\% del total de noticias sobre el «Brexit» incluyeron posiciones políticas plurales. Sin embargo, el aparente pluralismo político que reflejaron los medios se vio atemperado por el hecho de que en las noticias con posiciones plurales el $37,50 \%$ de las fuentes citadas mostraron opiniones a favor del «Brexit» mientras el 59,37\% manifestaron una posición a favor de la permanencia del Reino Unido en la UE. Solo un 3,12\% de las fuentes citadas expresaron una posición indefinida al respecto. 
Gráfico n. ${ }^{\circ}$ 10. Posturas políticas reflejadas en las informaciones sobre el «Brexit»

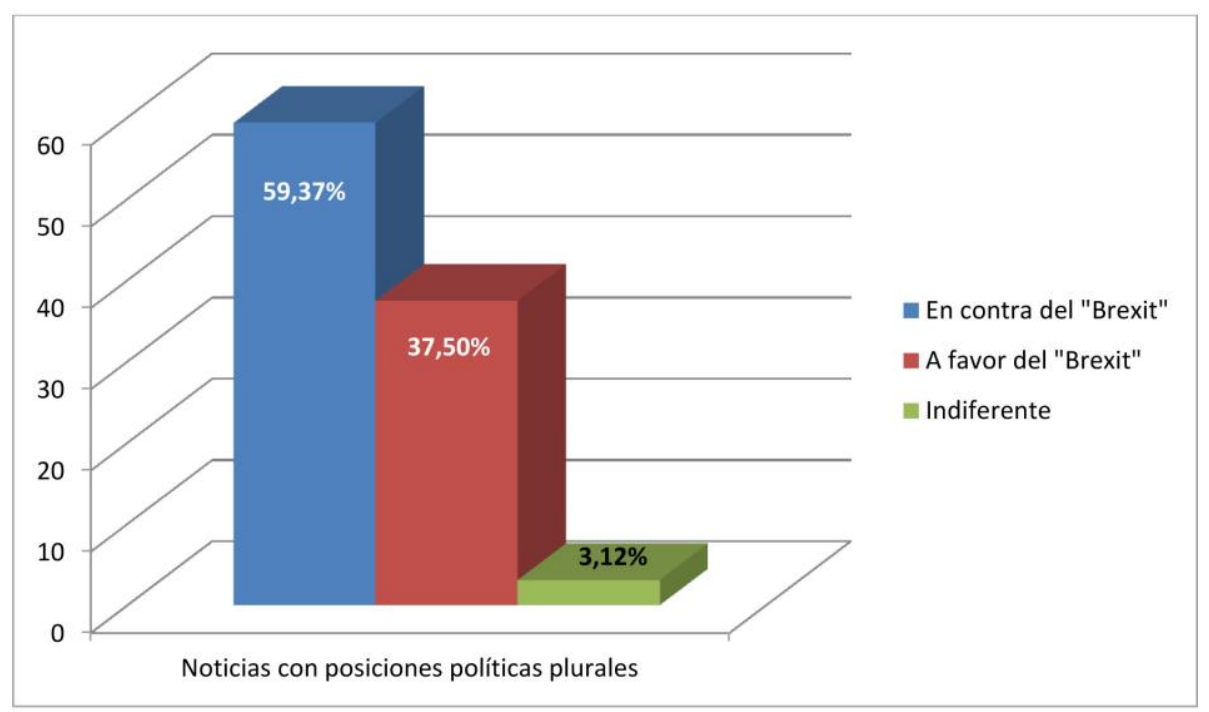

Fuente: elaboración propia.

En las piezas que reflejaron una posición única sobre el Brexit se citó una sola fuente en el $66,66 \%$ de los casos y solo dos fuentes en el 33,33\% restante. Por el contrario, en las piezas que expresaron distintas posiciones políticas sobre el Brexit se citaron entre dos y cuatro fuentes en el 90,91\% de los casos y una única fuente de información en un reducido porcentaje de casos. En estas piezas la única fuente citada se utilizó para reforzar una opinión política de las expresadas en la narración.

Gráfico n. ${ }^{\circ} 11$. Número de fuentes en noticias plurales sobre el «Brexit»

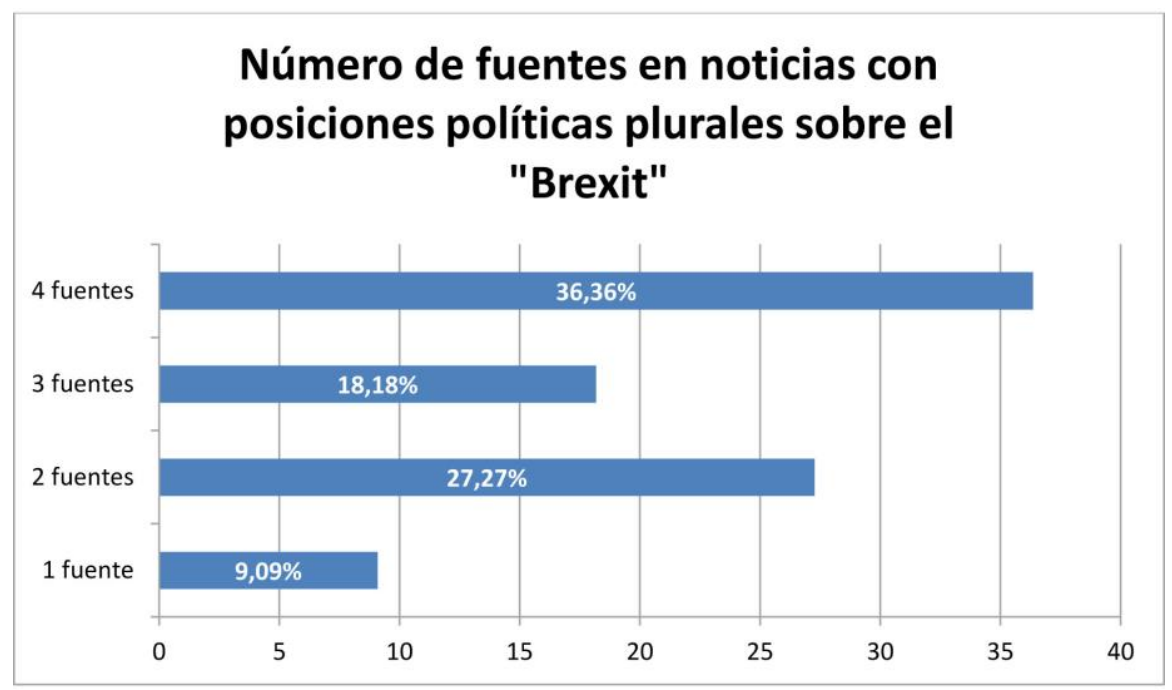

Fuente: elaboración propia. 
Como se puede apreciar, el pluralismo político de los medios resultó ser más formal que real, puesto que un mayor número de fuentes citadas y un mayor número de piezas con posturas divergentes no garantiza la representación de ideas políticas plurales, sino en ocasiones más bien el refuerzo de posturas políticas posiblemente prefijadas por la línea editorial de cada medio.

\section{DISCUSIÓN}

Los resultados de la investigación respecto al grado de pluralismo informativo registrado en las informaciones sobre asuntos europeos en televisión ponen parcialmente en cuestión las teorías de Watts y Maddison, 2014, p. 109 respecto a la tendencia actual a reducir el número de fuentes de información y a privilegiar la presencia de representantes gubernamentales. En la investigación se detectaron nueve tipos diferentes de fuentes de información, una cifra global estimable, si bien se debe tener en cuenta que la media de fuentes empleadas en cada categoría de noticia -con fuentes directas, con fuentes indirectas o con ambas- osciló entre 1,80 y 3,85. Además, la representación de cada uno de los nueve tipos de fuentes fue variable y frente a la mayor presencia de fuentes oficiales y cívicas, casi no se registraron fuentes de uso más habitual en los informativos anglosajones como los expertos o los propios periodistas como voz autorizada a la hora de realizar análisis propios de los hechos.

La presencia de fuentes oficiales y de las élites fue mayor en noticias con fuentes indirectas y en noticias con ambos tipos de fuentes, lo que vendría a confirmar las teorías del sector mayoritario de la doctrina (Tutchman, 1978; Gans: 1979; Power y Self, 2003, p. 101; Shehata, 2007, p. 149; Watts y Maddison, 2014, p. 109). Sin embargo, este patrón no se reprodujo en el caso de las noticias con fuentes directas -las más numerosas- donde se detectó una presencia equilibrada de fuentes oficiales y de origen ciudadano. Los resultados registrados propician por tanto una reflexión sobre la validez de los dos modelos defendidos por la doctrina sobre la mayor presencia de fuentes de una y otra naturaleza en los informativos de televisión.

\section{CONCLUSIONES}

El análisis de las fuentes de información en los informativos de televisión generalista de las cadenas de televisión españolas ha permitido establecer un patrón informativo según el cual las noticias que incluyen declaraciones a cámara de fuentes de información son más numerosas que las citaciones indirectas en una proporción del 60\%-40\%. La media de fuentes de información citadas oscila entre 2,14 y 1,80 según se trate de fuentes directas o indirectas, aunque llega a alcanzar la estimable cifra de 3,85 fuentes en las escasas piezas informativas editadas con fuentes directas e indirectas.

Se identificaron hasta nueve tipos distintos de fuentes de información (institucionales, gubernamentales, políticas, agentes sociales, cívicas, sociedad civil, expertos, mediáticas y estadísticas/documentales), lo que en un principio indicaría la existencia de un pluralismo informativo más que aceptable. Sin embargo, los resultados demostraron que en el escenario informativo español todavía se margina el uso útil de fuentes de calidad como los expertos (más habituales en otros sistemas informativos internacionales), las fuentes estadísticas y documentales y a los propios medios de comunicación como fuente de información confiable para la audiencia.

A pesar de que se observa un incremento de la presencia ciudadana a través de las opiniones de ciudadanos anónimos, representantes de la sociedad civil (ONG) y encuestas de opinión, se mantiene la tradicional polarización entre las fuentes oficiales y de las élites y las fuentes cívicas, que fueron ambas las más numerosas en todos los casos analizados. Las fuentes oficiales fueron más frecuentemente citadas y visibilizadas mediante el uso de formatos y técnicas de refuerzo (totales e imágenes 
coordinadas con la narración en VTR) tanto en noticias con fuentes indirectas como en noticias que incluyeron fuentes directas e indirectas al mismo tiempo.

Esta circunstancia situaría al caso español dentro del modelo de predominio de fuentes oficiales sostenido por la mayoría de la doctrina (Gans, 1979; Power y Self, 2003, p. 101; Shehata, 2007, p. 149; Watts y Maddison, 2014, p. 109). Sin embargo, en las noticias con fuentes directas (las más numerosas de la investigación), se registró una situación de absoluto equilibrio entre fuentes oficiales y cívicas, lo que colocaría al caso español del lado del modelo equilibrado que proponen otras investigaciones (Schlesinger, 1990, pp. 61-83; Papas, 1991; Cross, 2010, p. 419).

En definitiva, solo pueden confirmarse las dificultades a la hora de determinar un modelo informativo definido en relación con el uso de las fuentes en televisión, lo que sostendría las teorías de Dimitrova y Strömbäck (2009, pp. 149-166) sobre los problemas para establecer en el momento actual modelos de representación de fuentes fidedignos que no estén basados en estudios aislados sobre hechos noticiosos específicos o registrados en un único medio de comunicación.

El análisis del pluralismo político en noticias europeas a través de las fuentes de información sugiere que las cadenas de televisión españolas siguen expresando una orientación europeísta evidente caracterizada por la inclusión en la agenda informativa de un volumen significativo de asuntos típicamente institucionales y por el uso extensivo de fuentes de información también institucionales. Por otra parte, la «nacionalización» de los asuntos europeos se detectó como una práctica habitual de los medios españoles, aunque la elevada presencia de noticias sobre los Estados miembros que incluyeron otras perspectivas informativas sugiere que se están produciendo avances positivos en el tratamiento plural de la información en televisión.

Sin embargo, el volumen de noticias sobre posiciones políticas alternativas a las oficiales y al proceso de integración europeo fue minoritario y en ellas se dio un pluralismo más formal que real, con informaciones que introdujeron fuentes de información diversas pero que transmitieron, o bien posiciones únicas, o bien posturas claramente mayoritarias a favor de una determinada opción política.

La investigación ha intentado aportar datos actualizados sobre el uso de las fuentes de información en noticias sobre asuntos europeos en el medio televisivo español y ha demostrado que existe un pluralismo informativo relativo, centrado en distintos tipos de fuentes oficiales y de origen ciudadano, pero que no origina necesariamente la existencia de un pluralismo político análogo.

Se entiende que el trabajo de investigación llevado a cabo es replicable y que su contraste serviría para verificar si existe un patrón común respecto al uso de las fuentes de información en noticias sobre asuntos europeos o bien si, por el contrario, el comportamiento de las fuentes en este tipo de información especializada no se distingue del general registrado en estudios previos en el medio televisivo, como así parecen sugerir en parte los datos analizados en la investigación.

\section{BIBLIOGRAFÍA}

Cross, K. A. (2010). Experts in the News: The differential use of sources in election Television news. Canadian Journal of Communication, 35(3), 413-429.

Deuze, M. (2002). National News Cultures: a comparison of Dutch, German, British, Australian, and U.S. Journalists. Journalism \& Mass Communication Quarterly, 79(1), 134-149.

De Vreese, C. H., Peter, J. y Semetko, H. A. (2001). Framing politics at the launch of the euro: A cross-national comparative study of frames in the news. Political Communication, 18(2), 107-122.

Dimitrova, D. V. y Strömbäck, J. (2009). The Conditionality of Source Use: comparing source use in U.S. and Swedish television media. Journal of Global Mass Communication, 2(1/2), 149-166. 
Fico, F. G. y Soffin, S. (1994). Covering Local Conflict: Fairness in Reporting a Public Policy Issue. Newspaper Research Journal, 15(4), 64-76.

Fishman, M. (1980). Manufacturing the newss. Austin, Texas: University of Texas Press.

Gans, H. J. (1979). Deciding what's news: A study of CBS Evening News, NBC Nightly News, Newsweek and Time. New York, NY: Vintage Books.

Hackett, R. A. (1985). A hierarchy of access: Aspects of source bias in Canadian Tv news. Journalism Quarterly, 62(2), 256-265 y 277.

Hall, S., Clark, J. N., Critcher, C., Jefferson, T. y Roberts, B. (1978). Policing the crisis: Mugging, the state, and law and order. London: Macmillan.

Hallin, D. C. y Mancini, P. (2004). Comparing media systems. Three models of media and politics. New York: Cambridge University Press.

Hjarvard, S. (2006). Tv-nyheder. En Dansk tv's historie (pp. 105-144). Copenhagen: Samfundslitteratur.

Hopmann, D. N. y Shehata, A. (2011). The contingencies of ordinary citizen appearances in political television news. Journalism Practice, 5(6), 657-671.

Humanes, M. L., Montero Sánchez, M. D., Molina de Dios, R., López-Berini, A. L. (2013). Pluralism and political parallelism in Spanish television news programmes. Revista Latina de Comunicación Social, 68, 566-581.

Lawrence, R. G. (2000). The politics of force: Media and the construction of police Brutality. Berkeley: University of California Press.

Lewis, J., Wahl-Jorgensen, K. e Inthorn, S. (2004). Images of Citizenship on Television News: constructing a passive public. Journalism Studies, 5(2), 153- 164.

Lewis, J. y Wahl-Jorgensen, K. (2005). Active Citizen or Coach Potato? Journalism and public opinion. En S. Allan (Ed.), Journalism: Critical Issues (pp. 98-108). Maidenhead, Berkshire: Open University Press.

Miller, A. y Kurpius, D. (2010). A citizen-eye view of television news source credibility. American Behavioral Scientist, 54(2), 137-157.

Owens, L. C. (2008). Network News: The Role of Race in Source Selection and Story Topic. The Howard Journal of Communications, 19, 355-370.

Papas, L. K. (1991). Notable quotables: A study of source selection in local television news. Tesis de maestría no publicada. Kingston, ON: Queen's University.

Peter, J. (2004). Our long «return to the concept of powerful mass media» - a cross national comparative investigation of the effects of consonant media coverage. International Journal of Public Opinion Research, 16(2), 144-168.

Peter, J., Lauf, E. y Semetko, H. A. (2004). Television coverage of the 1999 European Parliamentary Elections. Political Communication, 21(4), 415-433.

Powell, L. y Self, W. (2003). Government Sources Dominate Business Crisis Reporting. Newspaper Research Journal, 24(2), 97-107.

Pradel Miquel, M. (2008). Europa en la prensa española. Papers: Revista de Sociología, 87, 235-252.

Riegert, K. (2011). Pondering the Future for Foreign News on National Television. International Journal of Communication, 5, 1567-1585.

Rössler, P. (2004). Political communication messages: Pictures of our world on international television news. En Comparing political communication: Theories, cases and challenges. Cambridge: Cambridge University Press. 
Schlesinger, P. (1990). Rethinking the sociology of journalism: Source strategies and the limits of media centrism. En M. Ferguson (Ed.), Public communication: The new imperatives: future directions for media research (pp. 61-83). London: Sage Publications.

Shehata, A. (2007). Facing the Muhammad cartoons: Official dominance and event driven news in Swedish and American elite press. The Harvard International Journal of Press/ Politics, 12(4), 131-153.

Tuchman, G. (1978). Making news: A study in the construction of reality. New York, NY: Free Press.

Watts, R. y Maddison, J. (2014). Print News Uses More Source Diversity Than Does Broadcast. Newspaper Research Journal, 35(3), 107-118.

\section{Fonseca, Journal of Communication}

